\title{
AS PRODUÇÕES ACADÊMICAS SOBRE AS PARCERIAS PÚBLICO-PRIVADAS NA EDUCAÇÃO INFANTIL.
}

Ana Paula Gianfelice, Silvio César Nunes Militão

Universidade Estadual Paulista - UNESP, Programa de Pós-Graduação em Educação, Presidente Prudente, SP. E-mail: anapaula.0287@hotmail.com.

\section{RESUMO}

O presente artigo apresenta dados parciais da nossa pesquisa de mestrado cujo objetivo é mapear as produções acadêmicas, desde 1998, sobre as parcerias firmadas entre os setores público e privado no âmbito da educação infantil, mais especificamente, na creche, onde se encontram crianças de 0 a 3 anos. Exporemos, então, os resultados de um levantamento bibliográfico de estudos cujo tema é a parceria entre os setores público e privado, publicados em periódicos da área da educação. Os resultados mostram que essa prática tem se tornado corriqueira nas cidades do Brasil, uma vez que os municípios esbarram na lei de responsabilidade fiscal, não podendo ultrapassar o teto de gastos da folha pública. Concluímos que tal prática tem sido uma saída plausível para as prefeituras. No entanto, a transferência de recursos para o terceiro setor acaba gerando gastos muito altos para os cofres públicos.

Palavras-chave: educação infantil, creche, parceria público-privada.

\section{THE ACADEMIC PRODUCTIONS ON PUBLIC-PRIVATE PARTNERSHIPS IN CHILD EDUCATION.}

\begin{abstract}
This text presents partial data from our master's research whose objective is to map the academic productions, since 1998, on the partnerships established between the public and private sectors in the field of pre-school education, specifically in the nursery, where children from 0 to 3 years. We will then present the results of a bibliographic survey of studies whose theme is the partnership between the public and private sectors, published in periodicals in the area of education. The results show that this practice has become commonplace in cities in Brazil, since the municipalities run counter to the fiscal responsibility law, and can not exceed the public spending ceiling. We conclude that it has been a plausible solution for municipalities. However, the transfer of resources to the third sector ends up generating very high expenses for the public coffers.
\end{abstract}

Keywords: child education, day care, public-private partnership. 


\section{INTRODUÇÃO}

Com a publicação de dispositivos legais, como a Constituição Federal e a Lei de Diretrizes e Bases Nacionais (LDB), o atendimento na Educação Infantil passa a ser direito garantido à criança de 0 a 3 anos, cabendo aos municípios a responsabilidade de ofertar essas vagas em creches. No entanto, com o aumento substancial da demanda de matrículas, as vagas ofertadas pela esfera pública tornaram-se insuficientes, aumentando, assim, os convênios entre os setores público e o privado.

Na LDB, a educação infantil passou a ser caracterizada como primeira etapa da educação básica, sendo dividida em creches e pré-escolas, conforme explicita seu artigo 29:

A educação infantil, primeira etapa da educação básica, tem como finalidade o desenvolvimento integral da criança de até 5 (cinco) anos, em seus aspectos físico, psicológico, intelectual e social, complementando a ação da família e da comunidade. (BRASIL, 1996).

Após a regularização da educação infantil como direito público e subjetivo, as crianças conquistaram ganhos significativos no âmbito da educação formal de 0 a 5 anos. Porém, neste trabalho trataremos da idade específica de 0 a 3 anos.

O objetivo deste estudo foi mapear as produções acadêmicas que tratam da temática parceria público-privada na educação infantil e entender as razões que levaram os municípios a contratarem o terceiro setor para suprir a carência de vagas no âmbito da escola pública.

\section{METODOLOGIA}

A partir de uma abordagem de natureza qualitativa, nesta pesquisa foi usada como metodologia a bibliográfica, conforme cita o autor:

[...] a pesquisa bibliográfica é feita a partir do levantamento de referências teóricas já analisadas, e publicadas por meios escritos e eletrônicos, como livros, artigos científicos, páginas de web sites. Qualquer trabalho científico inicia-se com uma pesquisa bibliográfica, que permite ao pesquisador conhecer o que já se estudou sobre o assunto. Existem, porém, pesquisas científicas que se baseiam unicamente na pesquisa bibliográfica, procurando referências teóricas publicadas com o objetivo de recolher informações ou conhecimentos prévios sobre o problema a respeito do qual se procura a resposta (FONSECA, 2002, p. 32).

Elencamos três plataformas para realização da busca por produções acadêmicas a respeito do tema parceria público-privada na educação infantil, a saber: Portal SciELO (Scientific Electronic Library Online), Portal de Periódicos da Plataforma CAPES (Coordenação de Aperfeiçoamento de Pessoal de Nível Superior) e a Plataforma dos encontros anuais da Associação Nacional de Pós-Graduação e Pesquisa em Educação (ANPED). Nesta última, a consulta foi a partir da 23a Reunião Anual, que aconteceu no período de 24 a 28 de setembro de 2000, em Caxambu - MG, restringindo-se ao grupo de trabalho 05, Estado e Política Educacional, e ao grupo 07, Educação da criança de 0 a 6 anos. O período pesquisado foi de 1998 até 2018.

\section{RESULTADOS}

Para efetuar o levantamento das produções acadêmicas sobre as parecerias públicoprivadas na educação infantil utilizamos alguns descritores que já haviam sido pré-determinados. Porém, durante a pesquisa surgiu a necessidade de usarmos apenas palavras nas buscas dos artigos científicos para compor este estudo. As palavras-chave usadas enfocaram na educação infantil, gestão conveniada e demais formas de atendimento do terceiro setor, conforme se lê no Quadro 1. 
Quadro 1. Descritores de busca utilizados na pesquisa.

\begin{tabular}{|l|l|}
\hline Palavras-chave 1 & Palavras-chave 2 \\
\hline Educação infantil conveniada & Conveniada \\
\hline Gestão compartilhada na educação infantil & Compartilhada \\
\hline Oferta / atendimento na educação infantil & Oferta / atendimento \\
\hline Parceria público-privada na educação infantil & Parceria público-privada \\
\hline Subvenção pública à educação infantil privada & \\
\hline
\end{tabular}

Fonte: Quadro organizado pelos autores, a partir do levantamento efetuado.

A partir da utilização dos descritores supracitados, encontramos um total de 10 trabalhos acerca da temática em abordagem, conforme demonstrado pelo Quadro 2:

Quadro 2. Relação de trabalhos selecionados: título, autor (es) e ano de publicação.

\begin{tabular}{|c|c|c|}
\hline Títulos dos trabalhos & Autor & Ano \\
\hline $\begin{array}{l}\text { Políticas públicas para a educação infantil em } \\
\text { Goiânia: a luta por um projeto político-social. }\end{array}$ & $\begin{array}{l}\text { Ivone Garcia Barbosa; Nancy } \\
\text { Nonato de Lima Alves; Telma } \\
\text { Aparecida Teles Martins; Solange } \\
\text { M. O Magalhães. }\end{array}$ & 2005 \\
\hline $\begin{array}{l}\text { A educação infantil via programa bolsa creche: } \\
\text { O caso do município paulista de Hortolândia. }\end{array}$ & Cássia Alessandra Domiciano. & 2011 \\
\hline $\begin{array}{l}\text { Financiamento da educação infantil em seis } \\
\text { capitais Brasileiras. }\end{array}$ & Marcos Edgar Bassi. & 2011 \\
\hline $\begin{array}{l}\text { As parcerias entre prefeituras paulistas e o } \\
\text { setor privado na política educacional: } \\
\text { Expressão de simbiose? }\end{array}$ & $\begin{array}{l}\text { Thereza Adrião; Teise Garcia; } \\
\text { Raquel Borghi; Lisete Arelaro. }\end{array}$ & 2012 \\
\hline $\begin{array}{l}\text { Arranjos institucionais entre o poder Público } \\
\text { municipal e instituições privadas para oferta } \\
\text { de vagas na educação infantil. }\end{array}$ & $\begin{array}{l}\text { Jaqueline dos Santos Oliveira; } \\
\text { Raquel Fontes Borghi. }\end{array}$ & 2013 \\
\hline $\begin{array}{l}\text { Educação infantil e políticas municipais: Um } \\
\text { estudo longitudinal. }\end{array}$ & $\begin{array}{l}\text { Maria Fernanda Rezende Nunes; } \\
\text { Patrícia Corsino; Sonia Kramer. }\end{array}$ & 2013 \\
\hline $\begin{array}{l}\text { Gestão da educação infantil nas políticas } \\
\text { municipais. }\end{array}$ & $\begin{array}{l}\text { Sonia Kramer; Leonor Pio Borges } \\
\text { de Toledo; Camila Barros. }\end{array}$ & 2014 \\
\hline $\begin{array}{l}\text { O atendimento privado subsidiado na } \\
\text { educação infantil: os convênios e contratos } \\
\text { administrativos em análise. }\end{array}$ & $\begin{array}{l}\text { Caroline de Fátima Nascimento de } \\
\text { Jesus Azevedo; Raquel Fontes } \\
\text { Borghi. }\end{array}$ & 2015 \\
\hline $\begin{array}{l}\text { Que educação é pública? Análise preliminar do } \\
\text { atendimento conveniado na educação infantil } \\
\text { nas diferentes regiões administrativas } \\
\text { brasileiras. }\end{array}$ & $\begin{array}{l}\text { Raquel Fontes Borghi; Regiane } \\
\text { Helena Bertagna. }\end{array}$ & 2016 \\
\hline $\begin{array}{l}\text { Judiciário e políticas públicas: o caso das vagas } \\
\text { em creches na cidade de São Paulo. }\end{array}$ & $\begin{array}{l}\text { Vanessa Elias de Oliveira; Mariana } \\
\text { Pereira da Silva; Vitor Marchetti. }\end{array}$ & 2018 \\
\hline
\end{tabular}

Fonte: Quadro organizado pelos autores, a partir do levantamento efetuado.

A partir dos dados dispostos no quadro 2 constatamos que as publicações concernentes ao tema investigado são recentes, uma vez que a primeira publicação selecionada tem data de 2005. Podemos observar, também, que houve um interstício entre uma publicação e as outras, já que as próximas duas ocorreram no ano de 2011, sendo posteriormente seguidas por publicações dos anos de 2012, 2013, 2014, 2015 e 2016, e a última publicação selecionada ocorreu no corrente ano (2018). 


\section{DISCUSSÃO}

Para a discussão dos resultados faz-se necessário, inicialmente, apresentar - mesmo brevemente - cada um dos 10 trabalhos selecionados. Segue, então, uma breve síntese dos trabalhos que selecionamos para o primeiro grupo:

- Barbosa e colaboradoras (2005) fazem um relato sobre a educação infantil no município de Goiânia, discutindo o modo de constituição desta, seu desenvolvimento e descrevendo as parcerias existentes entre os setores público-privado e mostrando dados relevantes acerca dos convênios firmados com entidades sem fins lucrativos;

- Domiciano (2011) faz uma análise do programa bolsa creche, que consiste na estratégia do município de Hortolândia em comprar vagas para alunos na rede particular de ensino, na etapa da creche e pré-escola. Deste modo, acontece uma subvenção do público à educação privada. $\mathrm{O}$ trabalho buscou dados financeiros ligados à implantação do programa, concluindo que $98 \%$ dos convênios firmavam-se com escolas privadas, diferenciando-se das instituições sem fins lucrativos;

- Oliveira e Borghi (2013) mapeiam as parcerias entre o setor público e o privado e os convênios firmados para a oferta da educação infantil, constatando que o município usa dessa estratégia para atender a demanda das vagas em creches, incluindo as entidades com fins lucrativos;

- Nunes, Corsino e Kramer (2013) realizaram, por meio de questionários, pesquisas longitudinais para identificar como os municípios organizam a educação infantil e fazem a sua cobertura, bem como, tratam da formação de seus profissionais e quais recursos financeiros e materiais empregam. Em relação aos convênios, especificamente, destacam que houve aumento no número de professores da administração municipal cedidos para as instituições do terceiro setor;

- Kramer, Toledo e Barros (2014) apresentam um estudo sobre as políticas públicas municipais voltadas à educação infantil no Rio de Janeiro, quinze anos após a aprovação da LDB. As autoras usaram como instrumento a aplicação de questionários, realizaram entrevistas com os profissionais e observações das práticas na educação infantil. Como resultados, constataram que as municipalidades fazem diferentes tipos de convênios, desde a cessão de professores até a cessão de prédios;

- Oliveira, Silva e Marchetti (2018) relatam brevemente como o poder judiciário tem interferido na agenda do governo paulistano no atendimento à falta de vagas das creches e pré-escolas, citando a educação como direito público e subjetivo. Apresentam importantes dados relativos às creches que funcionam via convênio em prédios municipais próprios ou alugados pela prefeitura de São Paulo e são administrados pelo Terceiro Setor.

A seguir uma breve descrição dos trabalhos que compõem o segundo grupo:

- Bassi (2011), por sua vez, apresenta uma comparação entre o campo da educação em seis capitais brasileiras, tratando da municipalização do ensino, do seu financiamento e da transferência de recursos públicos para a manutenção das unidades voltadas à educação infantil sem fins lucrativos;

- A publicação de Azevedo e Borghi (2015) teve como objetivo analisar os instrumentos jurídicos adotados pelas prefeituras concernentes às parcerias firmadas com as instituições com fins lucrativos. Revelam que as prefeituras 
fixam prazos longos para a vigência de tais parcerias, deixando, inclusive, expresso a possibilidade de prorrogá-las.

- Borghi e Bertagna (2016) fizeram um levantamento dos municípios brasileiros que atendem crianças da educação infantil por meio dos convênios, colhendo os dados no site do Fundo Nacional de Desenvolvimento da Educação (FNDE). As autoras constataram que o maior número de convênios entre os setores público e privado concentram-se nas regiões Sul e Sudeste, junto a instituições confessionais e filantrópicas comunitárias sem fins lucrativos;

- Adrião e colaboradoras (2012) apresentam as consequências das parcerias entre os setores público e privado, evidenciando que o processo de municipalização pode ter influência nas parcerias entre prefeituras e setor privado lucrativo e não lucrativo;

Ao final das apresentações dos trabalhos notamos que fazem parte do primeiro grupo as pesquisas que tratam das políticas educacionais na busca do atendimento a educação infantil de 0 a 3 anos, o modo como são empregados os recursos nas creches e como as prefeituras se organizam para atender a demanda por vagas nesta etapa de ensino, descrevem também as consequências advindas das parcerias firmadas entre poder público e as entidades com ou sem fins lucrativos, os autores elencados neste grupo são: Barbosa e colaboradoras, 2005; Domiciano, 2011; Oliveira e Borghi, 2013; Nunes, Corsino e Kramer, 2013; Kramer, Toledo e Barros, 2014; Oliveira, Silva e Marchetti 2018.

No outro grupo estão reunidos os trabalhos que tratam do financiamento dessas parcerias entre as prefeituras e as entidades, as transferências dos recursos, bem como as estratégias do legislativo na aplicação dos recursos públicos à esfera privada, tratam destes temas os autores Bassi, 2011; Azevedo e Borghi 2015; Borghi e Bertagna, 2016; Adrião e colaboradoras, 2012.

Findando as apresentações e análise dos trabalhos que foram separados em dois grupos, podemos concluir é que o primeiro conjunto de pesquisas vem ao encontro da minha proposta de trabalho uma vez que trata da fonte de financiamento, a implantação dos recursos públicos ao setor privado.

Já o segundo grupo tem pouca semelhança com o meu tema e minha proposta de investigação, uma vez que este grupo está voltado aos instrumentos jurídicos utilizados na garantia da vaga nas creches e nas regiões com mais incidências das parcerias. Sendo assim este grupo de pesquisas embora aborde temas importantes, não vem ao encontro da minha proposta de trabalho.

\section{CONCLUSÃO}

No forte contexto da lei de responsabilidade fiscal, os municípios precisam respeitar o teto de gastos com os investimentos em diversos setores de sua competência. Sendo assim, na pasta da educação, os administradores públicos encontraram como saída a terceirização das creches para atender a demanda pela procura de vagas de crianças de 0 a 3 anos.

Mediante os trabalhos encontrados, podemos inferir que o interesse pela pesquisa do tema em questão surgiu por volta do ano de 2005, ano de publicação do primeiro artigo selecionado para este trabalho. No entanto, a maior concentração dos trabalhos está entre os anos de 2011 a 2016.

Em suma, as pesquisas selecionadas tratam do financiamento dessas parcerias públicoprivadas, o modo como os municípios organizam o atendimento das crianças e uma dessas pesquisas compara cidades Brasileiras, mostrando a transferência de recursos públicos ao setor privado. 
Os estudos mostram que as transferências de recurso para estas instituições do setor privado são altas, na grande maioria das cidades brasileiras e que as prefeituras têm preferido esse tipo de parceria em detrimento de abrir novas escolas somente geridas pelo poder público, uma vez que notadamente suas responsabilidades são transferidas para o terceiro setor.

\section{REFERÊNCIAS}

ADRIÃO, Theresa; GARCIA, Teise; BORGHI, Raquel; ARELARO, Lisete. As parcerias entre prefeituras paulistas e o setor privado na política educacional: expressão de simbiose? Educação \& Sociedade (Impresso), Campinas, v. 33, p. 533 - 549, 2012.

AZEVEDO, Caroline de Fatima Nascimento de Jesus; BORGHI, Raquel. O atendimento privado subsidiado na educação infantil: os convênios e contratos administrativos em análise. Educação, Rio Claro, v. 25, p. 1 - 15, 2015.

BRASIL. Ministério da Educação. Lei no 9394 de 20 de dezembro de 1996. Estabelece as Diretrizes e Bases da Educação Nacional. Disponível em: <http://www.planalto.gov.br/Ccivil_03/leis/L9394.htm>. Acesso em: agosto de 2018.

BASSI, Marcos. Financiamento da educação infantil em seis capitais brasileiras. Cadernos de Pesquisa, São Paulo, v. 41, n. 142, p. 116 - 141, jan./abr. 2011. https://doi.org/10.1590/S010015742011000100007

BARBOSA, Ivone; ALVES, Nancy Nonato; MARTINS, Telma Aparecida; MAGALHÃES, Solange. Políticas públicas para a educação infantil em Goiânia: a luta por um projeto político-social. Caxambu: ANPED, 2005.

BORGHI, Raquel; BERTAGNA, Regiane Helena. Que educação é pública? Análise preliminar do atendimento conveniado na educação infantil nas diferentes regiões administrativas brasileiras. Revista Brasileira de Estudos Pedagógicos RBEP-INEP, Brasilia, v. 97, p. 506 - 517, 2016. https://doi.org/10.1590/s2176-6681/278133671

DOMICIANO, Cássia Alessandra. A educação infantil via programa bolsa creche: o caso do município paulista de Hortolândia. Educação em revista [online], Belo Horizonte, vol. 27, n.3, p.231-250, 2011.

FONSECA, J. J. S. Metodologia da pesquisa científica. Fortaleza: UEC, 2002.

GIL, A. C. Como elaborar projetos de pesquisa. São Paulo: Atlas, 2002.

KRAMER, Sonia; TOLEDO, Leonor Pio Borges de; BARROS, Camila. Gestão da educação infantil nas políticas municipais. Revista Brasileira de Educação [online], Rio de Janeiro, vol.19, n.56, p.11-36, 2014.

NUNES, Maria Fernanda Rezende; CORSINO, Patricia; KRAMER, Sonia. Educação infantil e politicas municipais: um estudo longitudinal. Cadernos de Pesquisa, São Paulo, v.43, n 148, p.152-175, 2013. https://doi.org/10.1590/S0100-15742013000100008 
OLIVEIRA, Jaqueline Santos; BORGHI, Raquel. Arranjos institucionais entre o poder público municipal e instituições privadas para a oferta de vagas na educação infantil. Revista Brasileira de Estudos Pedagógicos (Impresso), Brasília, v. 94, p. 151 - 167, 2013.

OLIVEIRA, Vanessa Elias; SILVA, Mariana Pereira; MARCHETTI, Vitor. Judiciário e Políticas Públicas: A judicialização da educação infantil em São Paulo. Educação \& Sociedade, Campinas, v. 39, p. 119, 2018. 